\section{Azide-tagged Sphingolipids for the proteome-wide identification of C16- ceramide-binding proteins}

Janine Schulte-Zweckel, ${ }^{a}$ Tabea Schneidewind, ${ }^{a}$ Jose Luis Abad, ${ }^{b}$ Andreas Brockmeyer, ${ }^{\text {a }}$ Petra Janning, ${ }^{a}$ Gemma Triola ${ }^{b *}$

a)Department of Chemical Biology; Max-Planck-Institute of molecular Physiology; OttoHahn-Strasse 11, D-44227 Dortmund (Germany). b) Department of Biological

Chemistry; Institute of Advanced Chemistry of Catalonia (IQAC-CSIC), Spanish National Research Council (CSIC), Jordi Girona 18-26, 08034 Barcelona (Spain).

Ceramide plays key roles in autophagy, inflammation and apoptosis. However, little is known about the molecular mechanisms regulating its function and only a handful of cellular effectors are known for this lipid. Here we show that azide-tagged sphingolipids are powerful tools to identify ceramide targets. The combination of a protein array analysis and a mass spectrometrybased proteomic profiling successfully detects known ceramidebinding proteins and identifies others not yet reported, several of which we validated using a variety of techniques.

Ceramide is a key regulator of apoptosis with an ubiquitous role in additional biological processes. ${ }^{1}$ Although much effort has been done to dissect the sphingolipid-mediated pathways, we still lack a clear mechanistic understanding of how ceramide mediates those actions. Ceramide accumulation can cause changes in local membrane structures and lead to the formation of ceramide-enriched membrane domains, which are important platforms for signalling, viral infection and membrane trafficking. ${ }^{2}$ Alternatively, there are increasing evidences that bioactive lipids can exert their effects due to their ability to directly interact with specific protein targets, either to regulate their membrane localization or to modulate their activity. ${ }^{3}$ However, only a limited number of ceramide-interacting proteins are currently known ${ }^{4-6}$, including the inhibitor 2 of protein phosphatase $2 \mathrm{~A}\left(\right.$ (2PP2A), ${ }^{7}$ the atypical protein kinase $\mathrm{C}$ (PKC) $\zeta_{1}^{8}$, the kinase-suppressor of Ras $^{9}$ and Cathepsin D. ${ }^{10}$ Hence, new chemical tools capable of proteome-wide elucidation of ceramide-lipid interactions are needed.

The past decade has seen remarkable developments in the field of lipid-protein interactions, ${ }^{11}$ resulting in the establishment of novel methods that enabled a growing list of proteins interacting with cholesterol, fatty acids, phospholipids ${ }^{12-15}$ and sphingolipids. ${ }^{16,17}$ As a result, protein-lipid interactions, which have been generally considered as undruggable, have emerged as potential and promising novel therapeutic targets. Despite these tremendous efforts, systematic studies able to characterize relevant novel ceramide-protein interactions are still scarce. Some attempts have been made including proteomic approaches with a radiolabelled ceramide ${ }^{18}$ or a biotin conjugated 66 -ceramide ${ }^{4}$ and the use of yeast surface cDNA display combined with deep sequencing. ${ }^{19}$ More recently, a bifunctional ceramide modified at the $\mathrm{N}$-acyl chain has been employed to validate StarD7 as a novel ceramide binding protein. ${ }^{20}$

Ceramides can be $\mathrm{N}$-linked to different fatty acids (C14-C26) and specific chain lengths effects have been described for the different ceramide species. Thus, whereas C16-Cer seems to be

propapoptotic, C24-Cer may have protective effects. However, only a limited number of cases have explored the role of the fatty acid in the specific interaction of ceramide with protein targets $^{21}$ and most of the proteomic studies are done with short-chain and/or biotinylated ceramide analogues. Sphingosines bearing a omega-terminal azide $\left(\omega N_{3}\right)$ have been recently shown to be recognised by the biosynthetic machinery and incorporated into sphingolipid metabolic pathways, thus suggesting that $\omega \mathrm{N}_{3}$-sphingolipids may be good candidates to uncover unknown ceramide targets. ${ }^{22,23}$ Herein, we present an azide-tagged ceramide acylated with palmitic acid ( $\left.\omega \mathrm{N}_{3} \mathrm{C} 16 \mathrm{Cer}\right)$ and show that is a powerful tool to identify novel C16-ceramidebinding proteins.

To identify molecular targets of C16-ceramide we first used the azido tagged $\omega \mathrm{N}_{3} \mathrm{C} 16 \mathrm{Cer}(\mathbf{1})$ together with a mass spectrometrybased method for the proteome-wide identification of interacting proteins. To avoid rapid deacylation of $\omega_{3} \mathrm{C} 16 \mathrm{Cer}$ and reacylation to form other ceramide species, pull-down studies were performed in cell lysates. ${ }^{24}$ To this end, the $\omega \mathrm{N}_{3} \mathrm{C} 16 \mathrm{Cer}$ was captured onto dibenzocyclooctyne (DBCO) agarose via $\mathrm{Cu}(\mathrm{I})$-free strain-promoted alkyne-azide click chemistry (SPAAC) and treated with cell lysates from the neuronal mouse cells Neuro2a (N2a) (Figure1). A palmitic acid derivative, resembling the $N$-acylated chain of ceramide both in hydrophobicity and charge, was employed as a negative control to discard proteins that may bind to ceramide via non-specific hydrophobic interactions.

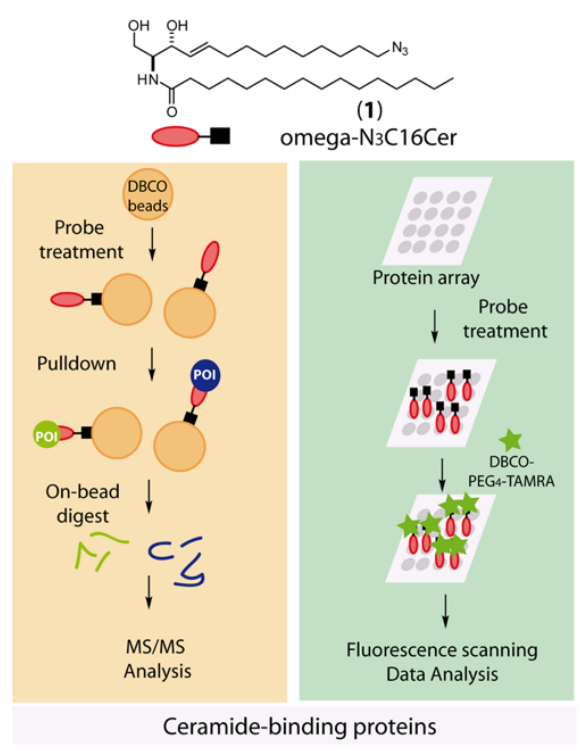

Figure 1. Schematic representation of the identification of ceramide-protein complexes. Cell lysates were treated with $\omega_{\mathrm{N}} \mathrm{C} 16$-Cer (1). Protein-lipid complexes were digested and analysed by mass spectrometry. Additionally, a proteome array was treated with $\omega \mathrm{N}_{3} \mathrm{C} 16-\mathrm{Cer}$ and bound ceramide was visualized by treatment with DBCO-PEG 4 -TAMRA. 
After on-bead digestion, peptides were eluted and analysed by mass spectrometry. The proteomic analysis of protein-lipid complexes was then performed yielding a final list of 214 potential targets (Table S1, ESI + ). Proteins were considered hits if the intensity of the protein after affinity enrichment using $\omega \mathrm{N}_{3} \mathrm{C} 16 \mathrm{Cer}$ as a bait was at least ten times higher than the intensity of the same protein in the negative control. Gratifyingly, this group contains many proteins functionally related to sphingolipid metabolism. These include acid ceramidase (ASAH1), ceramide synthase (CerS2, CerS4) and sphingomyelin phosphodiesterase (SMPD3 and SMPD4) and known ceramide binders such as the apoptosis regulator $\mathrm{BAX}^{25}$ and the protein phosphatase PP2A.

We next investigated the binding of $\omega N_{3} \mathrm{C} 16 \mathrm{Cer}$ using a proteome microarray containing over 9000 human proteins immobilized in duplicate under non-denaturating conditions. To this end, the array was incubated for one hour with $\omega \mathrm{N}_{3} \mathrm{C} 16 \mathrm{Cer}$. After several washing steps, the array was treated with dibenzocyclooctyne-PEG4-tetramethylrhodamine (DBCO-PEG4TAMRA) enabling copper-free labelling of bound ceramide (Figure 1). Ceramide-binding proteins were then visualized using a fluorescence microarray scanner. ${ }^{26,27}$ This approach yielded a list of 127 proteins including known ceramide interacting proteins such as CerS2 and CerS4 and the autophagy marker LC3 (Table S2, ESI †). Using these two different approaches and by comparative analysis, several high confidence proteins were identified. Known interacting proteins ( $B A X$ and $B C L-X L$ ) and sphingolipid related enzymes such as ceramide synthase, acid ceramidase, sphingosine lyase, were removed thereby yielding a final list of 24 proteins (Table 1 ).

We next sought to validate representative ceramide-protein interactions. To start with, we selected nine protein candidates on the basis of their functional annotation with a special emphasis on processes related with cell death (AIFm2), protein localization (OXA1L) and trafficking (ERGIC1), or diseases (Alzheimer's APP, the frequently associated with cancer Gal-1, Gal-3, ${ }^{28}$ and PPT1, or the autophagy regulator mTOR).

At first, probe-binding proteins were validated in N2a cells lysates after pull-down with immobilized $\omega \mathrm{N}_{3} \mathrm{C} 16 \mathrm{Cer}$. The association of these proteins with the immobilized probe was investigated by SDS-PAGE and Western blotting using the corresponding antibodies. Positive interactions were assigned when proteins were identified as a hit in 5 out 5 independent experiments. As a result of these studies, association of ceramide could be confirmed for AIFm2, APP, BUD31, Gal-1, Gal-3, mTOR and PPT1 whereas the mitochondrial proteins ERGIC and OXA1L were discarded as potential interacting candidates (Fig. S1, ESI + ). Interaction with immobilized $\omega \mathrm{N}_{3} \mathrm{C} 16 \mathrm{Cer}$ could be also confirmed for the known binders $\mathrm{BAX}$, $B C L-X L$ and CERT, thus further validating the use of $\omega \mathrm{N}_{3} \mathrm{C} 16 \mathrm{Cer}$ as a pull-down probe.

Specificity of the ceramide-protein interactions was further examined using a competition-binding assay. Briefly, N2a cell lysates were treated with and excess of C16-ceramide (C16-Cer) prior to addition of the probe. In all the cases the presence of the unlabelled ceramide efficiently prevented the association of the proteins with $\omega \mathrm{N}_{3} \mathrm{C} 16 \mathrm{Cer}$ in a dose-dependent manner,
Table 1. Merged Table of ceramide-binding proteins from mass spectrometry and protein array approaches (see also Table S1 and Table S2, ESIt).

\begin{tabular}{|c|} 
Proteins \\
\hline Low mol. weight phosphotyrosine protein phos phatase \\
Apoptosis-inducing factor 2 \\
\hline Aldehyde dehydrogenase family 3 member B1 \\
Amyloid beta A4 protein; N-APP \\
\hline BCL2-interacting killer (apoptosis-inducing) \\
\hline Baculoviral IAP repeat-containing protein 5 \\
\hline Protein Bud31 homolog \\
\hline Cyclin-dependent-like kinase 5 \\
\hline Ubiquinone biosynthesis protein CoQ9, mitochondrial \\
\hline Endoplasmic reticulum-Golgi interm. compart. protein 1 \\
\hline Fatty acid desaturase 2 \\
\hline Phospholipid hydroperoxide glutathione peroxidase \\
Galectin-1 \\
\hline Galectin-3 \\
\hline Lysophospholipase-like protein 1 \\
\hline Serine/threonine-protein kinase mTOR \\
C-Myc-binding protein \\
\hline Mitochondria inner membrane protein OXA1L \\
Pyridoxal kinase \\
\hline Palmitoyl-protein thioesterase 1 \\
Prostaglandin E synthase 2 \\
GTP-binding protein SAR1b \\
Ubiquitin-protein ligase E3C \\
Ubiquitin-like protein 5 \\
\hline
\end{tabular}

whereas no protein signal could be detected in beads modified with the negative control, thus suggesting that proteins directly interact with C16-Cer (Figure 2).

We next investigated the cellular interaction between ceramide and the protein candidates using a cellular thermal shift assay (CETSA), which enables to assess ligand-protein interactions in physiologically relevant settings such as cells or cell extracts. Proteins complexed to a ligand tends to become more resistant against heat-induced unfolding. As a result, a shift in protein melting temperatures $\left(T_{\mathrm{m}}\right)$ is a strong indication of binding of the ligand to the protein. ${ }^{29}$

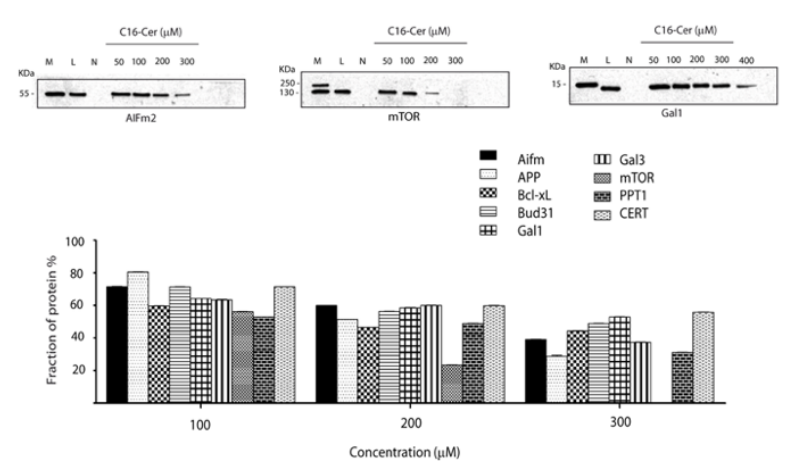

Figure 2. Competition profiles of $\omega \mathrm{N}_{3} \mathrm{C} 16 \mathrm{Cer}$ interaction with proteins were investigated using C16-Cer. N2a cell lysates were treated with increasing concentrations of ceramide before adding $\omega_{3} \mathrm{~N}_{3} \mathrm{C} 16 \mathrm{Cer}$. Verification was done by western blot of the samples using commercial antibodies specific to each protein. Representative blots for Aifm2, mTOR and Gal1 are shown. Protein content was normalized to untreated samples. M: marker, L: lysate, N: negative control. Data represent mean values $\pm S D ; n=3$. See also Figure $S 1$, ESI†. 


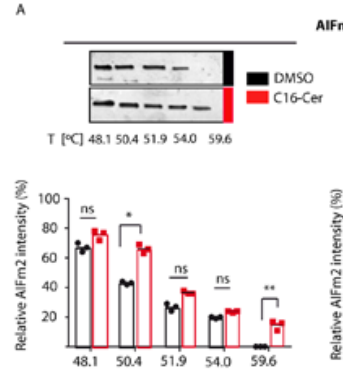

Temperature $[\mathrm{C} C]$
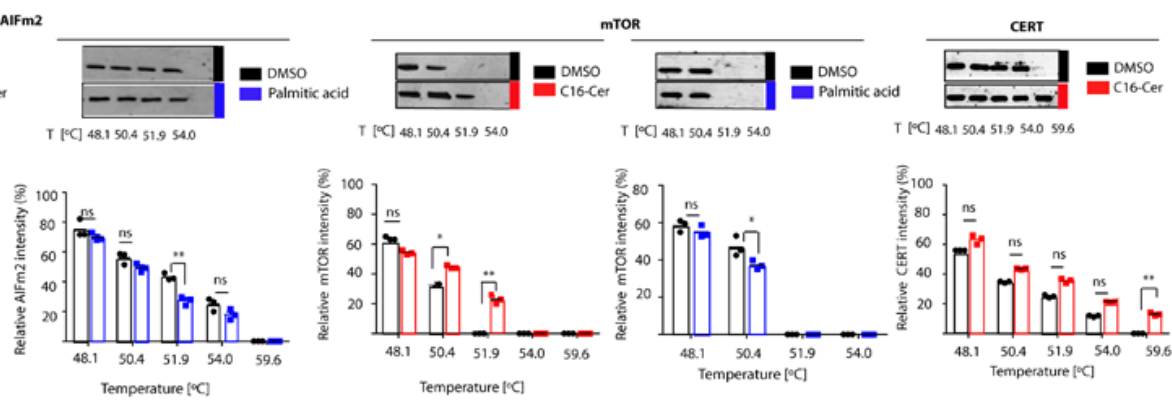

8
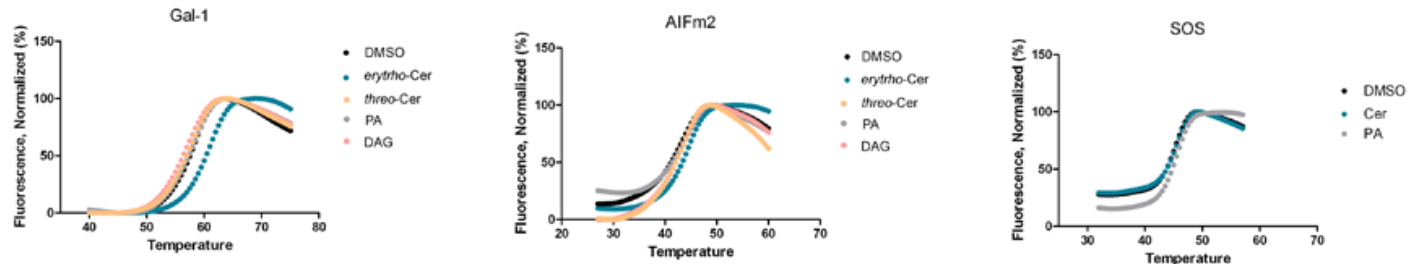

Figure 3. A) Cellular thermal shift assays were performed to measure the binding ability of C16-Cer to the tested proteins. Cell lysates were incubated with DMSO (1\%), with C16-Cer $(100 \mu \mathrm{M}, 1 \% \mathrm{DMSO})$ or with palmitic acid. Data was normalized to protein content $\left(42^{\circ} \mathrm{C}\right)$ and are presented as mean $\pm \mathrm{SD}(\mathrm{n}=3)$. A Student's two-tailed $\mathrm{t}$ test was used to determine $P$ values ${ }^{*} \mathrm{P}<0.05,{ }^{* *} \mathrm{P}<0.01$, NS: not significant. Representative results are shown for Aifm2, mTOR and CERT, see also Fig. S2 and S3, ESIt. B) Differential scanning fluorimetry. Experiments were performed in the absence of any compounds as a negative control (DMSO) and in the presence (10 $\mu \mathrm{M})$ of erytrho-Cer, threo-Cer, palmitic acid (PA) or diacylglycerol (DAG). The inflection point of each transition curve is considered the melting temperature $\left(T_{\mathrm{m}}\right)$ and the increase in $\Delta T_{\mathrm{m}}$ is an indication of binding. Similar results were obtained in the presence of a $50 \mu \mathrm{M}$ concentration of Cer: AlFm2 $\left(\Delta T_{\mathrm{m}}\right.$ of $\left.1.6^{\circ} \mathrm{C}\right)$ and Gal-1 $\left(\Delta T_{\mathrm{m}}\right.$ of $\left.3.9^{\circ} \mathrm{C}\right)$. See also Fig. S4, ESIt.

To this end, cell lysates were incubated with and without C16Cer $(100 \mu \mathrm{M})$ and heated to different temperatures.

After cooling, the samples were centrifuged to separate soluble fractions from precipitated proteins. The presence of the target protein in the soluble fraction was then analysed by western blotting. Binding of ceramide to the target proteins was assessed positive if at a certain temperature more protein could be significantly detected by Western blots in the ceramide treated group compared to the DMSO-treated group.

The known ceramide transport protein CERT was included as a positive control. Hence, treatment of the lysates with C16-Cer, resulted, in each instance, in an increase in thermal stability of the protein, indicating that $\mathrm{C} 16-\mathrm{Cer}$ binds the studied proteins and elicits this stabilization, thus confirming the protein-lipid interaction. This increase was significant in most of the cases and slight in others (APP, BUD31, PPT1) but always highly reproducible, whereas no thermal stabilization of AlFm2 or mTOR could be detected when cell lysates were treated with palmitic acid (Figure 3A, Figure S2 and S3, ESI+).

We next investigated whether ceramide directly binds the identified targets in vitro. Herein, we employed Differential Scanning Fluorimetry (DSF) which monitors the thermal unfolding of proteins in the presence of SYPRO Orange, a dye that fluoresce as it interacts with the hydrophobic regions of proteins that get exposed when the protein unfolds. ${ }^{30}$ The presence of a small-molecule binder causes the thermal stabilization of a protein, as determined by the increase of the protein-ligand complex melting temperature $\left(T_{\mathrm{m}}\right)$ compared to that of the apoprotein. This method has been successfully applied for the determination of lipid-protein interactions, such as the binding of hexadecanamide to the PPAR $\alpha^{31}$ or palmitic acid to the intestinal fatty acid binding protein (I-FABP) ${ }^{32}$ and detailed protocols have been described previously. ${ }^{33,34}$ C16-Cer $(10 \mu \mathrm{M})$ resulted in a marked stabilization toward Gal$1\left(\Delta T_{\mathrm{m}}\right.$ of $\left.3.7^{\circ} \mathrm{C}\right)$ and $\mathrm{BCL}-\mathrm{XL}\left(\Delta T_{\mathrm{m}}\right.$ of $\left.5.9^{\circ} \mathrm{C}\right)$, whereas a weaker binding could be observed for AlFm2 with $T_{\mathrm{m}}$ values below $2{ }^{\circ} \mathrm{C}$. No detectable temperature shifts could be observed when C16Cer was tested against Son of Sevenless (SOS) as a negative control or when AlFm2 and Gal-1 were treated with palmitic acid, whereas the binding of Palmitic acid to iFABP increased its $T_{\mathrm{m}}$ by $4.7^{\circ} \mathrm{C}$. To further explore the lipid binding specificity, we tested a threo isomer of ceramide ${ }^{37}$ and diacylglycerol (DAG). No binding was observed with these lipids to any of the tested proteins (Figure $3 \mathrm{~B}$ ). These results are good indication of specific binding of C16-Cer with Gal-1, AIFm2 and BCL-XL (Figure $3 \mathrm{~B}$ and $\mathrm{S} 4, \mathrm{ESI}+$ ).

The role of ceramide as a bioactive lipid is clear, but the precise mechanisms by which functions as a signalling molecule remain elusive. Hence, the identification of new ceramide-binding proteins may contribute to a detailed understanding of the underlying mechanism of ceramide signalling. To date, only a few ceramide-binding proteins have been identified and the list of targets is still not comprehensive to explain all its roles in regulating cell function. Moreover, relatively few studies have attempted the proteome-wide profiling of long-chain ceramidebinding proteins. Herein, we demonstrate that azide-tagged C16-ceramides are valuable tools for the identification of novel protein targets. The use of these chemical tools combined with a mass spectrometry-based proteomic approach and a proteome microarray analysis yielded a list of 214 and 127 potential interacting proteins respectively, among which 27 proteins overlapped. We initially chose nine potential candidates and binding could be confirmed for seven of them. Future experiments will be required to elucidate if ceramide 
binding directly affects protein activity or it modulates protein localization. We hope that these results show the great potential of azide-tagged sphingolipids as new tools to provide mechanistic insights into ceramide-mediated pathways.

The Dortmund Protein Facility is acknowledged for assistance in cloning, protein expression and purification. We would like to thank Dr. I. Vetter for fruitful discussion and for the generous gift of iFABP. The research leading to these results has received funding from the Max Planck Society (MPG Partner Group) and partial support from the Ministerio de Economia and Competitividad (grant CTQ2013-44334-P). G.T. thanks Prof. H. Waldmann for his constant and generous support.

\section{Conflicts of interest}

There are no conflicts to declare.

\section{Notes and references}

1 L. M. Obeid, C. M. Linardic, L. A. Karolak, Y. A. Hannun, Science 1993, 259, 1769.

2 K. Simons, M. J. Gerl, Nat. Rev. Mol. Cell Biol. 2010, 11, 688.

3 E. Muro, G. E. Atilla-Gokcumen, U. S. Eggert, Mol Biol Cell 2014, 25, 1819.

4 V. Kota, Z. M. Szulc, H. Hama, Proteomics 2012, 12, 2179.

5 R. D. Sentelle, C. E. Senkal, W. H. Jiang, S. Ponnusamy, S. Gencer, S. P. Selvam, V. K. Ramshesh, Y. K. Peterson, J. J. Lemasters, Z. M. Szulc, J. Bielawski, B. Ogretmen, Nat. Chem. Biol. 2012, 8, 831 .

6 C. F. Snook, J. A. Jones, Y. A. Hannun, Biochim. Biophys. Acta 2006, 1761, 927.

7 A. Mukhopadhyay, S. A. Saddoughi, P. Song, I. Sultan, S. Ponnusamy, C. E. Senkal, C. F. Snook, H. K. Arnold, R. C. Sears, Y. A. Hannun, B. Ogretmen, FASEB J. 2009, 23, 751.

8 G. Wang, J. Silva, K. Krishnamurthy, E. Tran, B. G. Condie, E. Bieberich, J. Biol. Chem. 2005, 280, 26415.

9 P. P. Ruvolo, Pharmacol. Res. 2003, 47, 383.

10 M. Heinrich, M. Wickel, W. Schneider-Brachert, C. Sandberg, J. Gahr, R. Schwandner, T. Weber, P. Saftig, C. Peters, J. Brunner, M. Kronke, S. Schutze, EMBO J. 1999, 18, 5252.

11 A. E. Saliba, I. Vonkova, A. C. Gavin, Nat. Rev. Mol. Cell Biol. 2015, 16, 753.

12 M. J. Niphakis, K. M. Lum, A. B. Cognetta, 3rd, B. E. Correia, T. A. Ichu, J. Olucha, S. J. Brown, S. Kundu, F. Piscitelli, H. Rosen, B. F. Cravatt, Cell 2015, 161, 1668.

13 J. J. Hulce, A. B. Cognetta, M. J. Niphakis, S. E. Tully, B. F. Cravatt, Nat. Methods 2013, 10, 259.

14 P. Haberkant, R. Raijmakers, M. Wildwater, T. Sachsenheimer, B. Brugger, K. Maeda, M. Houweling, A. C. Gavin, C. Schultz, G. van Meer, A. J. Heck, J. C. Holthuis, Angew Chem Int Ed Engl 2013, 52, 4033.

15 D. Wang, S. Du, A. Cazenave-Gassiot, J. Ge, J. S. Lee, M. R Wenk, S. Q. Yao, Angew Chem Int Ed Engl 2017, 56, 5829.

16 P. Haberkant, F. Stein, D. Hoglinger, M. J. Gerl, B. Brugger, P. P. Van Veldhoven, J. Krijgsveld, A. C. Gavin, C. Schultz, ACS Chem. Biol. 2016, 11, 222.

17 D. Hoglinger, A. Nadler, P. Haberkant, J. Kirkpatrick, M. Schifferer, F. Stein, S. Hauke, F. D. Porter, C. Schultz, Proc Natl Acad Sci U S A 2017, 114, 1566.

18 L. Elsen, R. Betz, G. Schwarzmann, K. Sandhoff, G. van Echten-Deckert, Neurochem. Res. 2002, 27, 717.

19 S. Bidlingmaier, K. Ha, N. K. Lee, Y. Su, B. Liu, Mol. Cell. Proteomics 2016, 15, 1232.
20 S. Bockelmann, J. G. M. Mina, S. Korneev, D. G. Hassan, D. Mueller, A. Hilderink, H. C. Vlieg, R. Raijmakers, A. J. R. Heck, P. Haberkant, J. C. M. Holthuis, J. Lipid Res. 2018, 59, 515.

21 S. Grosch, S. Schiffmann, G. Geisslinger, Prog Lipid Res 2012, $51,50$.

22 M. Garrido, J. L. Abad, A. Alonso, F. M. Goni, A. Delgado, L. R. Montes, J Chem Biol 2012, 5, 119.

23 M. Garrido, J. L. Abad, G. Fabrias, J. Casas, A. Delgado, ChemBioChem 2015, 16, 641.

24 H. J. Kim, Q. Qiao, H. D. Toop, J. C. Morris, A. S. Don, J. Lipid Res. 2012, 53, 1701.

25 M. N. Perera, S. H. Lin, Y. K. Peterson, A. Bielawska, Z. M. Szulc, R. Bittman, M. Colombini, Biochem. J. 2012, 445, 81.

26 E. C. Hett, R. E. Kyne, Jr., A. Gopalsamy, M. A. Tones, H. Xu, G. L. Thio, E. Nolan, L. H. Jones, ACS Comb Sci 2016, 18, 611

27 C. To, B. H. Shilton, G. M. Di Guglielmo, J. Biol. Chem. 2010, 285, 27944.

28 V. L. Thijssen, R. Heusschen, J. Caers, A. W. Griffioen, Biochim. Biophys. Acta 2015, 1855, 235.

29 D. Martinez Molina, R. Jafari, M. Ignatushchenko, T. Seki, E. A. Larsson, C. Dan, L. Sreekumar, Y. Cao, P. Nordlund, Science 2013, 341, 84.

30 M. W. Pantoliano, E. C. Petrella, J. D. Kwasnoski, V. S. Lobanov, J. Myslik, E. Graf, T. Carver, E. Asel, B. A. Springer, P. Lane, F. R. Salemme, J. Biomol. Screen. 2001, 6, 429.

31 A. Roy, M. Kundu, M. Jana, R. K. Mishra, Y. Yung, C. H. Luan, F. J. Gonzalez, K. Pahan, Nat. Chem. Biol. 2016, 12, 1075.

32 T. Velkov, M. L. Lim, J. Horne, J. S. Simpson, C. J. Porter, M. J. Scanlon, Mol. Cell. Biochem. 2009, 326, 87.

33 F. H. Niesen, H. Berglund, M. Vedadi, Nat. protoc. 2007, 2, 2212.

34 M. Vivoli, H. R. Novak, J. A. Littlechild, N. J. Harmer, J Vis Exp 2014, 51809.

35 T. Mejuch, H. van Hattum, G. Triola, M. Jaiswal, H. Waldmann, ChemBioChem 2015, 16, 2460.

36 J. C. Sacchettini, J. I. Gordon, L. J. Banaszak, J. Mol. Biol. $1989,208,327$.

37 T. Murakami, K. Furusawa, Tetrahedron 2002, 58, 9257.

38 J. Cox, M. Mann, Nat. Biotechnol. 2008, 26, 1367. 